\title{
CHEMO-INDUCED POD AND SEED MUTANTS IN MUNGBEAN (Vigna Radiata L. Wilczek)
}

\author{
M.R. Wani ${ }^{1 *}$, A.R. Dar ${ }^{1}$, A. Tak ${ }^{1}$, I. Amin ${ }^{1}$, N.H. Shah ${ }^{1}$, R. Rehman ${ }^{1}$, M.Y. \\ Baba $^{1}$, A. Raina ${ }^{2}$, R. Laskar ${ }^{2}$, M.I. Kozgar ${ }^{3}$ and S. Khan ${ }^{2}$ \\ ${ }^{1}$ Department of Botany, Abdul Ahad Azad Memorial Govt. Degree College, Bemina, Srinagar-190018, \\ Jammu and Kashmir, India \\ ${ }^{2}$ Mutation Breeding Laboratory, Department of Botany, Aligarh Muslim University, Aligarh-202 002, \\ Uttar Pradesh, India \\ ${ }^{3}$ KERB Biotech, Bemina, Srinagar-190018, Jammu and Kashmir, India
}

\begin{abstract}
Mungbean is one of the most important pulse crops due to its nutritive value and maintaining soil fertility through biological nitrogen fixation. Genetic variability is one of the pre-requisite for crop improvement. The present investigation was aimed at to enhance the genetic variability for three quantitative traits viz. pod length, number of seeds per pod and 100-seed weight in $M_{2}$ and $M_{3}$ generations of mungbean following mutagenesis with ethylmethane sulphonate (EMS), hydrazine hydrate $(\mathrm{HZ})$ and sodium azide (SA). Mean pod length did not differ significantly in most of the mutagenic treatments in $M_{2}$. However, significant improvement for the trait was exhibited with lower and moderate concentrations in $M_{3}$ generation. The mean number of seeds per pod and 100-seed weight increased with lower and moderate concentrations of the mutagens in $M_{2}$, whereas $M_{3}$ generation showed a complete positive trend of shift. Long pod and bold seeded mutants may be exploited to increase the number of seeds per pod and seed size leading to increased yield potential. The genotypic coefficient of variation, heritability and genetic advance increased manifold in the treated population for all these traits suggesting that mutagen induced variability has the substantial scope to improve the mungbean crop.
\end{abstract}

Keywords: Chemical mutagens, bold seeded mutants, enlarged pods, mungbean

\section{INTRODUCTION}

Pulses being rich in quality proteins, minerals and vitamins are inseparable ingredient of the diet of majority of Indian population (Siag et al., 2005). Indian population relies on pulses for meeting its protein requirement mainly because of its vegetarian

\footnotetext{
${ }^{*}$ Corresponding author e-mail: botanyrafiq@gmail.com
} 
food habit and high cost of animal-based protein. The country has witnessed a decreasing trend in the per capita availability of pulses from $61 \mathrm{~g}$ per day in 19511956 to less than $40 \mathrm{~g}$ in recent years (Satya Sundaram, 2010). The problem of declining per capita availability can be addressed through rapid improvement in indigenous production levels. Although efforts have been expedited to bring additional area under the cultivation of pulses, it is imperative to increase the production by exploiting the yield potential of existing varieties through genetic manipulation. Mungbean (Vigna radiata L. Wilczek), also known as green gram and mung, is native to India where it has been cultivated since ancient times. In India, mungbean was grown over an area of 3.38 million hectares with the production of 1.61 million tons in 2013-14 (www.iipr.res.in/e-pulse-data-book.html). The average seed yield of $474 \mathrm{~kg} \mathrm{ha}^{-1}$ is far below its presumed potential. It is cultivated mainly as kharif crop, but in southern India where winter is quite mild, it is grown as rabi crop. The crop can withstand drought but is susceptible to water logging. It is usually grown both as pure and mixed crop in different agro-ecological conditions. In addition to its nutritive value, it also has a unique property of maintaining and restoring soil fertility through biological nitrogen fixation (Stevenson and Van Kessel, 1996).

Mutation is an abrupt inheritable qualitative or quantitative change in the DNA sequence which is reflected in the change of sequence of corresponding RNA or protein molecules. Such a change may involve only one base/base pair or more than one base pair of DNA. Mutation breeding has an additional advantage when only one or two traits need improvement in an otherwise well adapted cultivar (Gottschalk, 1986, Joshua, 2000). Particularly, induction of micro-mutations in polygenic system controlling the quantitative traits is important for crop improvement. Several authors (Joshi and Verma, 2004, Khan and Wani, 2005, Singh et al., 2006, Auti, 2012, Bara et al., 2017, Wani, 2017, Patial et al., 2017) have reported in various crops that micro-mutations result in the release of considerable genetic variability in the mutagen treated population. Use of mutations to create genetic variability in the existing gene pool, can be very promising supplementary breeding activity.

Seed yield in pulses is a complex trait and is influenced by many other quantitative traits like fertile branches per plant, pods per plant, seeds per pod and 100-seed weight. Many breeders have so far reported increased seed yield per plant following mutagenesis with physical and chemical mutagens in different pulse crops. Waghmare and Mehra (2000) achieved considerably increased mean seed yield in $\mathrm{M}_{3}$ generation of Lathyrus sativus after treatments with gamma rays and EMS. Dadarwal and Mathur (2015) observed an increased seed yield in urdbean after mutagenic treatments with EMS, DMS and their combination with growth regulators like indole acetic acid (IAA) and gibberellic acid (GA). Similarly, Wani et al. (2012) reported a significant increase in mean seed yield in $\mathrm{M}_{3}$ and $\mathrm{M}_{4}$ generations of chickpea following mutagenesis with EMS and SA. The high yielding mutants will play an important role to break the yield constraints in pulse crops particularly mungbean. 
The agronomically and nutritionally superior mutants will serve as promising material to plant breeders in future and will economically benefit the resource poor farmers of rainfed areas especially in India.

Keeping above in view, the present study was undertaken to study the genetic basis of various quantitative traits viz. pod length, seeds per pod and 100-seed weight in $\mathrm{M}_{2}$ and $\mathrm{M}_{3}$ generations which directly impact the overall yield potential of mungbean.

\section{MATERIALS AND METHODS}

A field experiment was conducted during the kharif season of 2005, 2006 and 2007 at University Agricultural Farm, Aligarh Muslim University, Aligarh, Uttar Pradesh, India. Uniform and healthy seeds of mungbean (Vigna radiata L. Wilczek) var. NM1 were pre-soaked in distilled water for 9 hours prior to treatment with three chemical mutagens viz. $0.1,0.2,0.3 \%$ of ethylmethane sulphonate (EMS)- a monofunctional alkylating agent manufactured by Sissco Research Laboratories Pvt. Ltd., Mumbai, India and $0.01,0.02,0.03 \%$ of hydrazine hydrate (HZ)- a base analogue, manufactured by Qualigens Fine Chemicals, Mumbai and sodium azide (SA)- a respiratory inhibitor, manufactured by Indian Drugs and Pharmaceuticals Ltd., Hyderabad for 6 hours. The healthy, non-dormant and untreated seeds were soaked in distilled water for 15 hours and sown as control. The solutions of EMS and HZ were prepared in phosphate buffer of $\mathrm{pH} \mathrm{7,} \mathrm{whereas} \mathrm{SA} \mathrm{solution} \mathrm{was} \mathrm{prepared} \mathrm{in}$ phosphate buffer adjusted to $\mathrm{pH} 3$. Chemically treated seeds were thoroughly washed in running tap water to eliminate the residue mutagens from seed surface. Four hundred seeds for every treatment and control were sown in the field in complete randomized block design (CRBD) to raise $\mathrm{M}_{1}$ generation. The distance between the seeds in a row and between the rows was kept as $30 \mathrm{~cm}$ and $60 \mathrm{~cm}$, respectively. Seeds harvested from individual $\mathbf{M}_{1}$ plants were sown as $\mathbf{M}_{2}$ families in three replicates in the field. Seeds from each selected $\mathrm{M}_{2}$ progeny were bulked by taking an equal amount of seeds from each $\mathrm{M}_{2}$ progeny and thoroughly mixed. A random sample of this bulk was sown to obtain $\mathrm{M}_{3}$ progeny. Data collected for pod length (in $\mathrm{cm}$ ) and the mean for each plant was calculated for pod length, seeds per pods (fully matured pods were threshed and number of seeds per pod was counted) and 100-seed weight (weight of 100 seeds from each plant in g) isolated in $\mathrm{M}_{2}$ and $\mathrm{M}_{3}$ generations were subjected to statistical analysis according to Singh and Chaudhary (1985) in order to assess the extent of induced variation. The significance of difference between the means of treated and control population was tested by using least significant difference (LSD) estimated from the error mean square and tabulated ' $T$ ' value at $5 \%$ level of significance. 


\section{RESULTS AND DISCUSSION}

Success of any plant breeding programme depends on the presence of significant genetic variability, which permits effective selection. In recent years, mutation breeding has been gaining ground for inducing genetic resources (Datta et al., 1993). The direct use of mutations is valuable supplementary approach to plant breeding, particularly when it is desired to improve one or two easily identifiable characters in an otherwise well adapted variety. Induced mutations are thus the ultimate source of genetic variability in crop plants that may be difficult to bring through cross breeding procedures.

Three quantitative traits, namely pod length $(\mathrm{cm})$, number of seeds per pod and 100seed weight $(\mathrm{g})$ were statistically analyzed to assess the extent of induced variability in $\mathrm{M}_{2}$ and $\mathrm{M}_{3}$ generations. Pod mutations with increased length and girth over the control were recorded in $\mathrm{M}_{3}$ generation. The plants were normal in appearance with comparatively bigger pods. Plant height, primary branches per plant, pod length, seeds per pod and seed yield per plant was significantly increased over the control in these mutants. Data for pod length showed that most of the mutagen treatments were not proficient to induce significant differences in mean pod length in $\mathrm{M}_{2}$ generation. Also, the mean pod lengths shifted on either side of the control mean (Table 1). However, there was a significant increase in mean pod length with $0.02 \%$ (Figure 1b) and $0.03 \%$ of EMS treatments and with $0.02 \%$ of $\mathrm{HZ}$ and SA treatments in $\mathrm{M}_{3}$ generation.

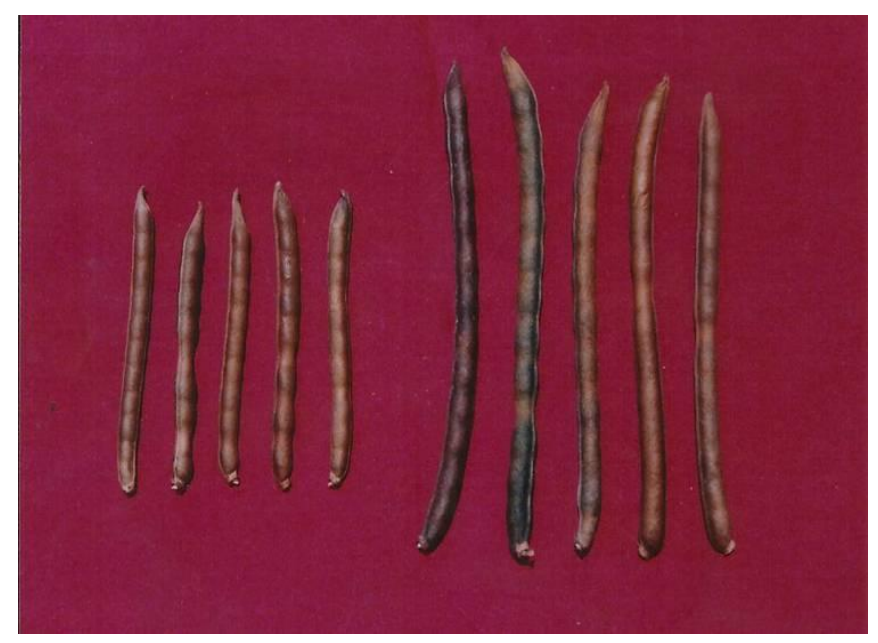

Figure 1. (a). Pods of var. NM-1 (control)

(b). Mutant isolated from $0.02 \%$ EMS in $\mathrm{M}_{3}$ generation showing increase in pod length and girth over the control 


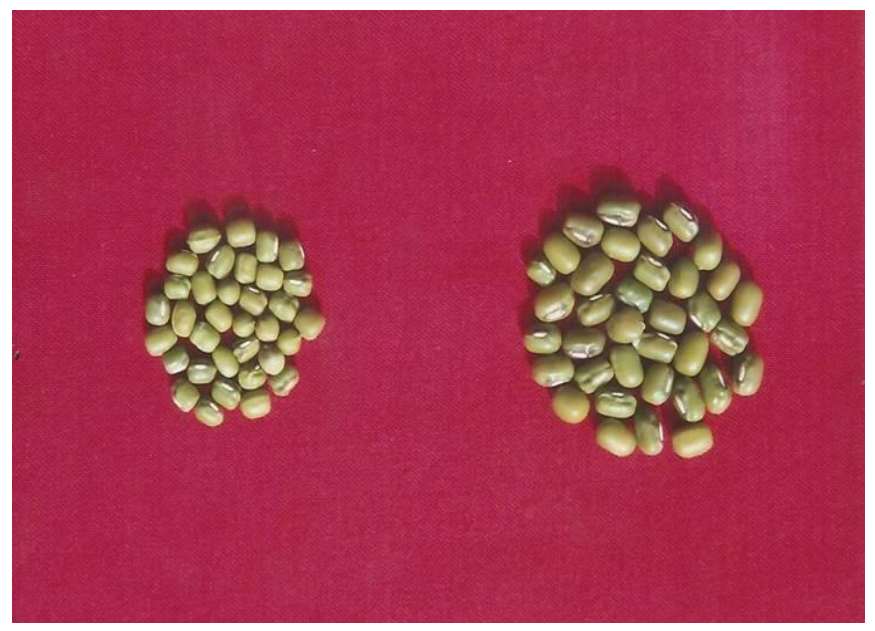

Figure 2. (a). Seeds of var. NM-1 (control)

(b). Bold seeds of the mutant isolated with $0.1 \% \mathrm{EMS}$ in $\mathrm{M}_{3}$ generation

Long pod mutant with increased girth is a useful variation and may be exploited to increase the number of seeds per pod and seed size leading to increased seed yield. Sharma and Singh (1992) and Wani et al. (2011) reported long pod mutants with gamma rays, EMS, HZ and SA in mungbean, while Singh and Agarwal (1986) reported long pod mutants with the treatments of EMS, gamma rays and their combination in cluster bean which had increased genetic and yield potential.

For seeds per pod, the mean shifted to both positive and negative directions in $\mathrm{M}_{2}$, but increased with all the treatments of the mutagens in $\mathrm{M}_{3}$ generation (Table 2). The increase was significant at lower and moderate concentrations in $\mathrm{M}_{2}$, which increased further in $\mathrm{M}_{3}$ generation. However, a reduction with highest mutagenic concentration in all the three mutagens was noticed in $\mathbf{M}_{2}$ generation. Khan (1985) assumed this depressive effect to be due to high seed sterility induced by higher doses of the mutagens. Similar results were reported by Singh and Chaturvedi (1990) in Lathyrus sativus and Singh et al. (2000) in Vigna mungo.

The mean 100-seed weight (g) showed a significant improvement over the control with lower and moderate mutagenic concentrations in $\mathbf{M}_{2}$ generation. However, it decreased at the highest concentration of the mutagens. In $\mathrm{M}_{3}$, mean 100-seed weight increased significantly with all the treatments (Table 3). The highest increase (bold seeds) was noticed with $0.1 \%$ EMS (Figure $2 b$ ) in $\mathrm{M}_{3}$ generation (control mean=3.71; treatment mean $=4.30$ ). Barshile (2006) also recorded bold seeded mutant in 'Vijay' and 'Virat' cultivars of chickpea. The mutant showed vigorous growth, significant increase in leaf area, number of seeds per pod and 100-seed weight over the control. Similarly, Singh et al. (2000) isolated a bold seeded mutant in urdbean following mutagenesis with gamma rays and EMS. This mutant showed vigorous growth and produced more leaves and pods per plant. 
Table 1. Estimates of mean values $(\overline{\mathrm{X}})$, shift in $\overline{\mathrm{X}}$ and genetic parameters for pod length (cm) in $\mathrm{M}_{2}$ and $\mathrm{M}_{3}$ generations of mungbean

\begin{tabular}{|c|c|c|c|c|c|c|}
\hline Treatment & Mean \pm S.E. & Shift in $\bar{X}$ & $\mathrm{PCV}(\%)$ & GCV (\%) & $\mathrm{h}^{2}(\%)$ & $\mathrm{GA}(\%$ of $\overline{\mathrm{X}})$ \\
\hline \multicolumn{7}{|c|}{$\mathrm{M}_{2}$ Generation } \\
\hline $0.1 \%$ EMS & $6.75 \pm 0.10$ & +0.50 & 9.75 & 5.20 & 28.40 & 7.31 \\
\hline $0.3 \%$ EMS & $6.15 \pm 0.08$ & -0.10 & 9.48 & 5.63 & 35.29 & 8.79 \\
\hline $\operatorname{LSD}(0.05)$ & & 0.52 & & & & \\
\hline $0.01 \% \mathrm{HZ}$ & $6.17 \pm 0.08$ & -0.08 & 9.31 & 5.37 & 33.33 & 8.12 \\
\hline $0.02 \% \mathrm{HZ}$ & $6.40 \pm 0.07$ & +0.15 & 8.58 & 5.18 & 39.28 & 8.58 \\
\hline $0.01 \% \mathrm{SA}$ & $6.30 \pm 0.07$ & +0.05 & 6.41 & 2.89 & 20.25 & 3.38 \\
\hline $0.02 \% \mathrm{SA}$ & $6.47 \pm 0.08$ & +0.22 & 8.60 & 4.63 & 29.03 & 6.62 \\
\hline $0.03 \% \mathrm{SA}$ & $6.37 \pm 0.06$ & +0.12 & 7.19 & 4.45 & 38.09 & 7.25 \\
\hline \multirow{2}{*}{\multicolumn{7}{|c|}{$\mathrm{M}_{3}$ Generation }} \\
\hline & & & & & & \\
\hline Control & $6.33 \pm 0.04$ & - & 4.74 & 2.23 & 2.78 & 22.22 \\
\hline $0.1 \%$ EMS & $6.58 \pm 0.13$ & +0.25 & 7.16 & 4.27 & 29.51 & 7.25 \\
\hline $0.02 \% \mathrm{HZ}$ & $6.78 \pm 0.09$ & +0.45 & 9.77 & 5.92 & 41.48 & 10.15 \\
\hline $0.03 \% \mathrm{HZ}$ & $5.97 \pm 0.08$ & -0.36 & 8.25 & 3.47 & 17.69 & 3.81 \\
\hline $\operatorname{LSD}(0.05)$ & & 0.25 & & & & \\
\hline $0.01 \% \mathrm{SA}$ & $6.52 \pm 0.04$ & +0.19 & 3.97 & 2.08 & 24.45 & 2.17 \\
\hline $0.02 \% \mathrm{SA}$ & $6.61 \pm 0.05$ & +0.28 & 4.34 & 2.28 & 27.50 & 2.68 \\
\hline $0.03 \% \mathrm{SA}$ & $6.48 \pm 0.06$ & +0.15 & 4.44 & 2.36 & 27.71 & 3.25 \\
\hline $\operatorname{LSD}(0.05)$ & & 0.22 & & & & \\
\hline
\end{tabular}

PCV $(\%)=$ Phenotypic coefficient of variation; GCV $(\%)=$ Genotypic coefficient of variation; $h^{2}(\%)=$ Heritability; GA $(\%)=$ Genetic advance 
Table 2. Estimates of mean values $(\overline{\mathrm{X}})$, shift in $\overline{\mathrm{X}}$ and genetic parameters for number of seeds per pod in $\mathrm{M}_{2}$ and $\mathrm{M}_{3}$ generations of mungbean

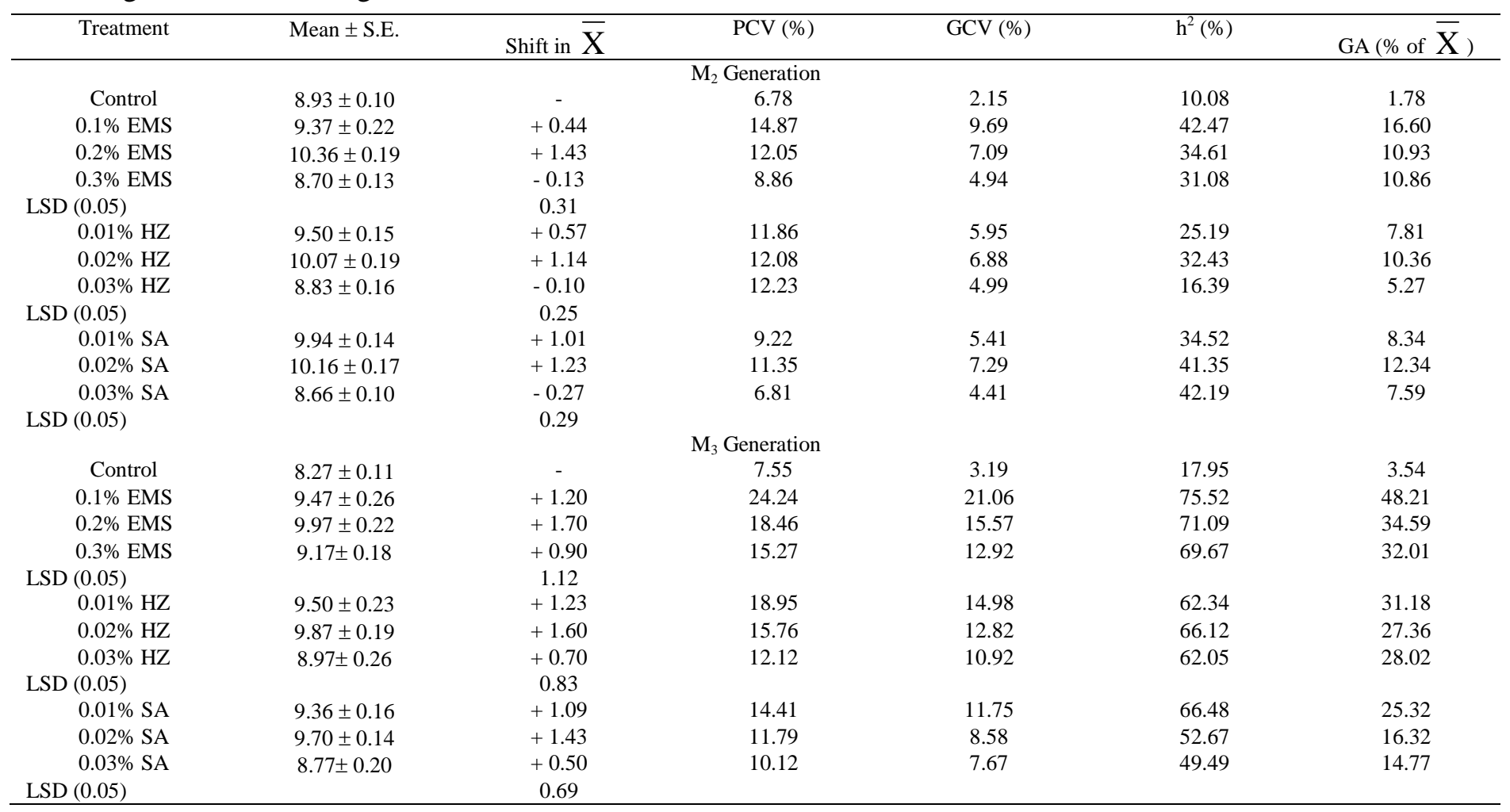

PCV $(\%)=$ Phenotypic coefficient of variation; GCV $(\%)=$ Genotypic coefficient of variation; $h^{2}(\%)=$ Heritability; GA $(\%)=$ Genetic advance 
Table 3. Estimates of mean values $(\bar{X})$, shift in $\bar{X}$ and genetic parameters for 100-seed weight (g) in $M_{2}$ and $M_{3}$ generations of mungbean

\begin{tabular}{|c|c|c|c|c|c|c|}
\hline Treatment & Mean \pm S.E. & Shift in $\bar{X}$ & $\overline{\mathrm{PCV}(\%)}$ & GCV (\%) & $\mathrm{h}^{2}(\%)$ & $\mathrm{GA}(\%$ of $\overline{\mathrm{X}})$ \\
\hline \multicolumn{7}{|c|}{$\mathrm{M}_{2}$ Generation } \\
\hline Control & $3.61 \pm 0.02$ & - & 2.90 & 1.52 & 27.27 & 1.99 \\
\hline $0.1 \%$ EMS & $3.87 \pm 0.04$ & +0.26 & 8.53 & 7.12 & 69.72 & 15.69 \\
\hline $0.3 \%$ EMS & $3.51 \pm 0.05$ & -0.10 & 9.56 & 7.50 & 61.60 & 15.52 \\
\hline $\operatorname{LSD}(0.05)$ & & 0.15 & & & & \\
\hline $0.01 \% \mathrm{HZ}$ & $3.96 \pm 0.05$ & +0.35 & 9.42 & 7.37 & 61.15 & 15.20 \\
\hline $\operatorname{LSD}(0.05)$ & & 0.12 & & & & \\
\hline $0.01 \% \mathrm{SA}$ & $3.78 \pm 0.04$ & +0.17 & 8.67 & 5.75 & 43.92 & 10.05 \\
\hline $0.02 \%$ SA & $3.82 \pm 0.04$ & +0.21 & 8.56 & 5.65 & 43.55 & 9.83 \\
\hline $0.03 \% \mathrm{SA}$ & $3.47+0.05$ & -0.14 & 8.88 & 5.23 & 34.73 & 8.18 \\
\hline $\operatorname{LSD}(0.05)$ & & 0.14 & & & & \\
\hline \multicolumn{7}{|c|}{$\mathrm{M}_{3}$ Generation } \\
\hline Control & $3.71 \pm 0.01$ & - & 2.62 & 1.04 & 15.79 & 1.09 \\
\hline $0.01 \% \mathrm{HZ}$ & $4.38 \pm 0.08$ & +0.67 & 13.26 & 12.02 & 82.19 & 28.66 \\
\hline $0.02 \% \mathrm{HZ}$ & $4.11 \pm 0.07$ & +0.40 & 13.14 & 11.15 & 72.41 & 25.11 \\
\hline $0.03 \% \mathrm{HZ}$ & $4.06 \pm 0.06$ & +0.45 & 12.63 & 10.97 & 70.14 & 23.82 \\
\hline $\operatorname{LSD}(0.05)$ & & 0.31 & & & & \\
\hline $0.01 \% \mathrm{SA}$ & $4.02 \pm 0.04$ & +0.31 & 9.08 & 6.72 & 54.88 & 13.15 \\
\hline $0.02 \% \mathrm{SA}$ & $4.17 \pm 0.05$ & +0.46 & 10.07 & 8.15 & 68.64 & 18.24 \\
\hline $0.03 \% \mathrm{SA}$ & $3.96 \pm 0.07$ & +0.25 & 9.63 & 7.97 & 65.14 & 16.82 \\
\hline $\operatorname{LSD}(0.05)$ & & 0.26 & & & & \\
\hline
\end{tabular}

PCV $(\%)=$ Phenotypic coefficient of variation; GCV $(\%)=$ Genotypic coefficient of variation; $h^{2}(\%)=$ Heritability; GA $(\%)=$ Genetic advance 
100 -seed weight is a dependable index of measuring yielding ability in pulse crops. 100-seed weight had shown a significant increase (boldness) over the control with most of the mutagenic treatments in both the generations. Bold seeded mutants isolated in various mutagenic concentrations in present study, showed 'gigas' characteristics and vigorous growth and may be utilized in various breeding programs as a donor parent for boldness character as also stated by Wani and Anis (2001) while studying mutagenesis in chickpea. Pawar (2011) has successfully used bold seeded mutants with higher 100-seed weight in cross breeding programmes.

The estimates of genetic parameters revealed a good degree of variability for pod length, seeds per pod and 100-seed weight in both $\mathrm{M}_{2}$ and $\mathrm{M}_{3}$ generations. The extent of variability induced by chemical mutagens differed in different traits. The quantitative traits, in general, have complex genetic determination involving large number of genes interacting with one another; consequently, variation in both the directions is expected. Variance level may be less responsive in one trait and highly responsive in other (Sharma, 1995). The phenotypic and genotypic coefficients of variation, heritability and genetic advance increased in all the treatments of mutagens over the control in both the generations for all the traits. High heritability in $\mathrm{M}_{3}$ generation indicated that the induced variability in mutant population has been fixed by selection. Heritability coupled with genetic advance is more helpful in predicting the effect of selection than the heritability alone because the heritability estimates are subjected to certain estimation errors (Lin et al., 1979).

In this study, the selection for pod length, seeds per pod and 100-seed weight were found to be effective in $\mathrm{M}_{3}$ generation. Therefore, these traits have high breeding significance in subsequent generations.

\section{CONCLUSION}

The narrow genetic base is a serious impediment to breeding progress in mungbean. Induced mutations can help to regenerate and restore the variability, which has been lost in the process of adaptation to various stresses or adaptation during the course of evolution. During the last decade, induced mutations have also been gaining increased importance in plant molecular biology as a tool to identify and isolate the genes and to study their structure and function. Knowledge of genes controlling important agronomic and quality traits is critical for plant breeders to develop proper strategies for efficient breeding programs. These techniques in combination with more efficient screening methods deserve special attention in the days ahead to make mungbean cultivation a promising, remunerative and viable option for pulse growing farmers of India. 


\section{REFERENCES}

Auti, S.G.(2012).Induced morphological and quantitative mutations in mungbean. Bioremediation, Biodiversity and Bioavailability, 6(1), 27-39.

Bara, B.M., Chaurasia, A.K., and Verma P. (2017). Gamma ray effect on frequency and spectrum of chlorophyll mutations in chickpea (Cicer arietinum L.) Journal of Pharmacognosy and Phytochemistry, 6(3), 590-591.

Barshile. (2006). Induction of genetic variability in Cicer arietinum employing sodium azide, ethylmethane sulphonate and gamma radiations. Ph.D thesis, University of Pune, India.

Dadarwal, M., and Mathur, V.L. (2015). Identification of early maturing high yielding mutants in blackgram (Vigna mungo L.) Hepper). Indian Journal of Agricultural Research, 49(5), 421-426.

Datta, R., Weichsellbaum, R., and Kufe D.W.(1993). Ionizing radiation down regulate histone $\mathrm{h}_{1}$ gene expression by transcriptional and post transcriptional mechanism. Radiation Research, 133, 176-181.

Gottschalk, W.(1986). Experimental mutagenesis in plant breeding. p.81-96. In A.B. Prasad (ed.), Mutagenesis: basic and applied. Print House, Lucknow, India

Joshi, P. and Verma, R.C. (2004). Radiation induced pod and seed mutants in faba bean (Vicia faba L.). Indian Journal of Genetics and Plant Breeding, 64(2), 155-156.

Joshua, D.C. (2000). Guidelines for successful mutation breeding. p. 21-26. In Proceedings of DAE-BRNS symposium on the use of nuclear and molecular techniques in crop improvement, Mumbai, India.

Khan, I.A. (1985). Mutation studies on mungbean (Vigna radiata (L.) Wilczek). X. Estimates of genetic variability. Bangladesh Journal of Scientific Research, 20(1-4), 189-195.

Khan, S., and Wani, M.R. (2005). Genetic variability and correlations studies in chickpea mutants. Journal of Cytology and Genetics, 6, 155-160.

Lin C.Y., Pevzner, I., and Friars, G.W.(1979.Experimental investigation of errors of heritability estimates in index selection. Canadian Journal of Genetics and Cytology, 21, 303-308.

Patial, K., Thakur, S.R., Singh K.P., and Thakur A. (2017). Frequency and spectrum of chlorophyll mutations and induced variability in rice bean (Vigna umbellata Thunb, Ohwi and Ohashi). Legume Research, 40(1), 39-46.

Pawar, S.E. (2011). Impact of mutant varieties of blackgram in realizing improved productivity. Mutation Breeding Newsletter, 45, 7-9.

Satya Sundaram, I. (2010). India needs a pulse revolution. Facts for You (Dec Issue):10-12

Sharma, B. (1995). Mutation breeding through induced polygenic variability. p. 1210-1219. In Proc. symposium of genetic research and education: current trends and the next fifty years, 3. 12-15 February, 1991. New Delhi, India.

Sharma, R., and Singh, V.P. (1992). The influence of altered moisture levels in seeds on the induction of mutations with EMS and gamma rays in mungbean. Journal of Indian Botanical Society, 71, 125-128. 
Siag, R.K., Gau, R.B., Singh, V., Prakash, V., and Verma, R.S. (2005). Studies on technology transfer through front line demonstration on mungbean semi-arid region of Rajasthan. Indian Journal of Pulses Research, 18(1), 64-66.

Singh, M., and Chaturvedi, S.N. (1990). Improvement of yield and quality character of Khesari dhal by use of mutagens. Mysore Journal of Agricultural Sciences, 24, 325330.

Singh, R.K., and Chaudhary, B.D. (1985). Biometrical methods in quantitative genetic analysis. Kalyani Publishers, Ludhiana, India.

Singh, S.P., Singh, N.K., Singh, R.P., and Prasad, J.P. (2006). Mutagenic effect of gamma rays and EMS on nodulation, yield and yield traits on lentil. Indian Journal of Pulses Research, 19(1), 53-55.

Singh, V.P., Singh, M., and Lal, J.P. (2000). Gamma ray and EMS induced genetic variability for quantitative traits in urdbean (Vigna mungo L.) Hepper). Indian Journal of Genetics and Plant Breeding, 60(1), 89-96.

Singh, V.P., and Agarwal, S. (1986). Induced high yielding mutants in cluster bean. Indian Journal of Agricultural Science, 56(10), 595-600.

Stevenson, F.C., and Van Kessel, C. (1996). The nitrogen and non nitrogen benefits of pea to eucceeding crops. Canadian Journal of Plant Science, 76, 735-745.

Waghmare, V.N., and Mehra, R.B. (2000). Induced genetic variability for quantitative characters in grasspea (Lathyrus sativus L.). Indian Journal of Genetics and Plant Breeding, 60(1), 81-87.

Wani, A.A., and Anis, M. (2001). Gamma ray induced bold seeded high yielding mutant in chickpea. Mutation Breeding Newsletter, 45, 20-21.

Wani, M.R., Khan, S., Kozgar, M.I., and Goyal, S.(2011). Induction of morphological mutants in mungbean (Vigna radiata (L.) Wilczek) through chemical mutagens. The Nucleus, 48 (3), 243-247.

Wani, M.R., Lone, M.A., Sheikh, S.A., Dar, M.S., Tak, M.A., Ahmad, P., and Khan, S. (2012). Induction and assessment of genetic variability for yield and yield contributing traits of chickpea (Cicer arietinum L.). Journal of Plant Genomics, 2(1), 28-33.

Wani, M.R. (2017). Induced chlorophyll mutations, comparative mutagenic effectiveness and efficiency of chemical mutagens in lentils (Lens culinaris Medik). Asian Journal of Plant Sciences, 16, 221-226, doi: 10.3923/ajps.2017 